\title{
Conformational, Vibrational Spectroscopic and Quantum Chemical Studies on 5-formyl-1h-pyrrole-2-carboxylic acid: A DFT Approach
}

\author{
S. Christopher Jeyaseelan, R. Mohamed Asath, R. Premkumar, \\ A. Milton Franklin Benial ${ }^{*}$ \\ PG and Research Department of Physics, N.M.S.S.V.N College, Madurai-625019, Tamilnadu, India
}

\begin{abstract}
The potential energy surface (PES) scan was performed for 5-formyl-1h-pyrrole-2-carboxylic acid (FHPC) molecule and the most stable optimized molecular structure was predicted using DFT/B3LYP method with 6-31G basis set. The theoretical vibrational frequencies were calculated for the optimized FHPC molecule using DFT/B3LYP method with cc-pVTZ basis set by Gaussian 09 Program package. The vibrational frequencies were assigned on the basis of potential energy distribution (PED) calculation using VEDA 4.0 program. The molecular reactivity, stability, intramolecular charge transfer studies and the calculation of ionization energy, electron affinity, global hardness, chemical potential, electrophilicity index and softness of the FHPC molecule were carried out using frontier molecular orbitals (FMOs) analysis. The bioactivity of the FHPC molecule was further confirmed using natural bond orbital (NBO) analysis.
\end{abstract}

Keywords: 5-formyl-1 h-pyrrole-2-carboxylic acids, PES scan, Vibrational analysis, FMOs, bioactivity

\section{Introduction}

Pyrrole is one of the most significant nitrogen containing aromatic five-membered ring present in large number of biologically active compounds having wide range of pharmaceutical applications. Pyrrole derivatives have potent biological activities such as antimicrobial, antiviral, anti-inflammatory and antitumor agents $[1,2]$. The different applications of the pyrrole compounds have attracted to study the spectroscopic and vibrational studies of its derivatives. In this present study, the potential energy surface scan, vibrational spectral analysis, FMOs and NBO analysis were carried out for the 5-formyl-1h-pyrrole-2-carboxylic acid (FHPC) molecule. The ionization energy, electron affinity, global hardness, chemical potential, electrophilicity index and softness values of the title molecule were also calculated.

\section{Computational Details}

The potential energy surface (PES) scan was performed to predict the most stable molecular structure of the FHPC molecule using DFT/B3LYP method with 6-31G basis set. The most stable molecular structure was optimized by DFT/B3LYP method with cc-pVTZ basis set using Gaussian 09 program [3]. The vibrational assignments were made with the high degree of accuracy on the basis of potential energy distribution (PED) calculation with the aid of VEDA 4.0 program and visualized by GaussView 05 program. GaussView 05 was used to visualize the frontier molecular orbitals. The NBO analysis was performed for the most stable FHPC molecule.

\subsection{Conformational analysis}

\section{Results And Discussion}

The PES scan was performed by changing the dihedral angle C4-C5-C10-H14 with step size $10^{\circ}$ ranging from $0^{\circ}$ to $360^{\circ}$ and kept all the other geometrical parameters are fixed. The plot between the relative energy and angle of rotation with respect to the dihedral angle derived from PES scan is shown in Fig.1. The FHPC molecule has three different conformers (I, II, III) with relative energies 0.0, 2.71, 14.98, $\mathrm{Kcal}^{\mathrm{mol}}{ }^{-1}$, respectively. The molecular structure corresponds to $0^{\circ}$ of dihedral angle C4-C5-C10-H14 in the PES scan was considered as the most stable conformer of the FHPC molecule. The conformer I and II are planar. The conformer II is located at the saddle point of the PES curve. Conformer III is highly unstable due to its nonplanar structure. 


\subsection{Vibrational spectral analysis}

The FHPC molecule has 15 atoms and 39 (3N-6) normal modes of vibrations, which belong to same symmetry (A) species. The FHPC molecule has $\mathrm{C}_{1}$ point group symmetry. None of the predicted vibrational frequencies have any imaginary frequency, implying that the optimized geometry is located at the local lowest point on the potential energy surface. All vibrations are both IR and Raman active. The vibrational assignments based on PED calculations were listed in Table 1 and simulated IR and Raman spectra were shown in Fig.2.

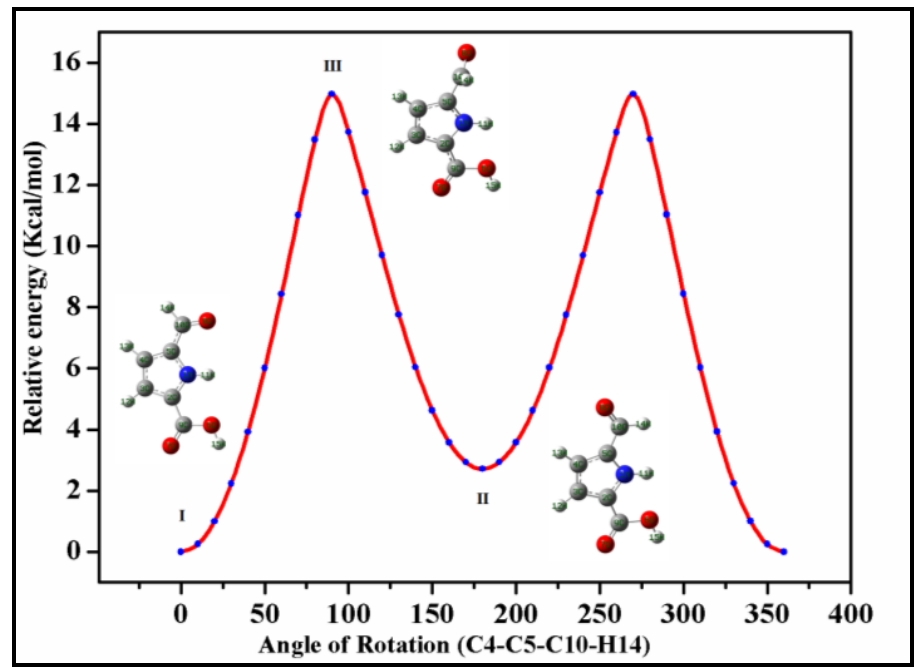

Fig.1. Conformational energy profile of the FHPC molecule

Table 1: Vibrational assignments of FHPC molecule with PED calculation

\begin{tabular}{|l|l|}
\hline Calculated wavenumbers $\left(\mathbf{c m}^{-1}\right)$ & Assignments with PED $(\%)$ \\
\hline 3758 & $v$ O-H $(100)$ \\
\hline 3632 & $v \varphi \mathrm{N}-\mathrm{H}(100)$ \\
\hline 3264 & $v \varphi \mathrm{C}-\mathrm{H}(99)$ \\
\hline 3242 & $v \varphi \mathrm{C}-\mathrm{H}(100)$ \\
\hline 2929 & $v \mathrm{C}-\mathrm{H}(99)$ \\
\hline 1802 & $v \mathrm{C}=\mathrm{O}(83)$ \\
\hline 1743 & $v \mathrm{C}=\mathrm{O}(85)$ \\
\hline 1586 & $v \varphi \mathrm{C}-\mathrm{C}(47), \beta \varphi \mathrm{N}-\mathrm{H}(14)$ \\
\hline 1519 & $v \varphi \mathrm{C}-\mathrm{C}(38), v \varphi \mathrm{C}-\mathrm{C}-\mathrm{N}(15)$ \\
\hline 1459 & $v \varphi \mathrm{C}-\mathrm{C}(17), v \varphi \mathrm{C}-\mathrm{N}-\mathrm{C}(22), \beta \mathrm{C}-\mathrm{H}(19)$, \\
\hline 1456 & $v \varphi \mathrm{C}-\mathrm{N}(38), v \varphi \mathrm{C}-\mathrm{C}(14), \beta \varphi \mathrm{N}-\mathrm{H}(18)$ \\
\hline 1369 & $v \varphi \mathrm{C}-\mathrm{N}(15), v \varphi \mathrm{C}-\mathrm{C}(10 \%), \beta \varphi \mathrm{C}-\mathrm{N}-\mathrm{C}(11)$ \\
\hline 1261 & $\rho \varphi \mathrm{C}-\mathrm{H}(53), v \varphi \mathrm{C}-\mathrm{N}(10), \beta \varphi \mathrm{N}-\mathrm{H}(22)$ \\
\hline 1114 & $\beta \mathrm{O}-\mathrm{H}(10), v \mathrm{C}-\mathrm{O}(42)$ \\
\hline 1064 & $\delta \mathrm{C}-\mathrm{H}(63), \beta \varphi \mathrm{C}-\mathrm{N}(16)$ \\
\hline 1017 & $\beta \varphi \mathrm{C}-\mathrm{N}(78)$, \\
\hline 919 & $\mathrm{t} \varphi \mathrm{C}-\mathrm{H}(85)$ \\
\hline 825 & $\omega \varphi \mathrm{C}-\mathrm{H}(83)$ \\
\hline 681 & $\eta \varphi \mathrm{N}-\mathrm{H}(77)$ \\
\hline 549 & $\eta \mathrm{O}-\mathrm{H}(78)$ \\
\hline$v$ - stretching, $\beta$ - in plane bending, $\rho-$ rocking, $\delta$-scissoring, $\eta$ - out of plane bending, $\omega-$ \\
wagging, t- twisting, $\varphi$-pyrrole ring. \\
\hline
\end{tabular}

\subsection{Frontier molecular orbitals analysis}

Fig.3 shows the FMOs of the FHPC molecule. The energy difference between the highest occupied molecular orbital (HOMO) and the lowest unoccupied molecular orbital (LUMO) is energy gap of the molecule. The calculated energy gap of the FHPC is $4.68 \mathrm{eV}$. The FMOs confirm the intramolecular charge transfer within the molecule and the higher band gap indicates the stability of the FHPC molecule. The energy needed to remove an electron from the filled orbital is known as ionization energy, which is obtained by $\mathrm{I}=-\mathrm{E}_{\mathrm{HOMO}}=7.05$ $\mathrm{eV}$ and the energy released when an electron is added to an unfilled orbital, which is termed as electron affinity, $\mathrm{A}=-\mathrm{E}_{\mathrm{LUMO}}=2.37 \mathrm{eV}$. The global hardness, electronegativity, chemical potential and electrophilicity index values of the molecule were calculated as $2.34,4.71,-4.71$ and $4.87 \mathrm{eV}$, respectively [4]. 


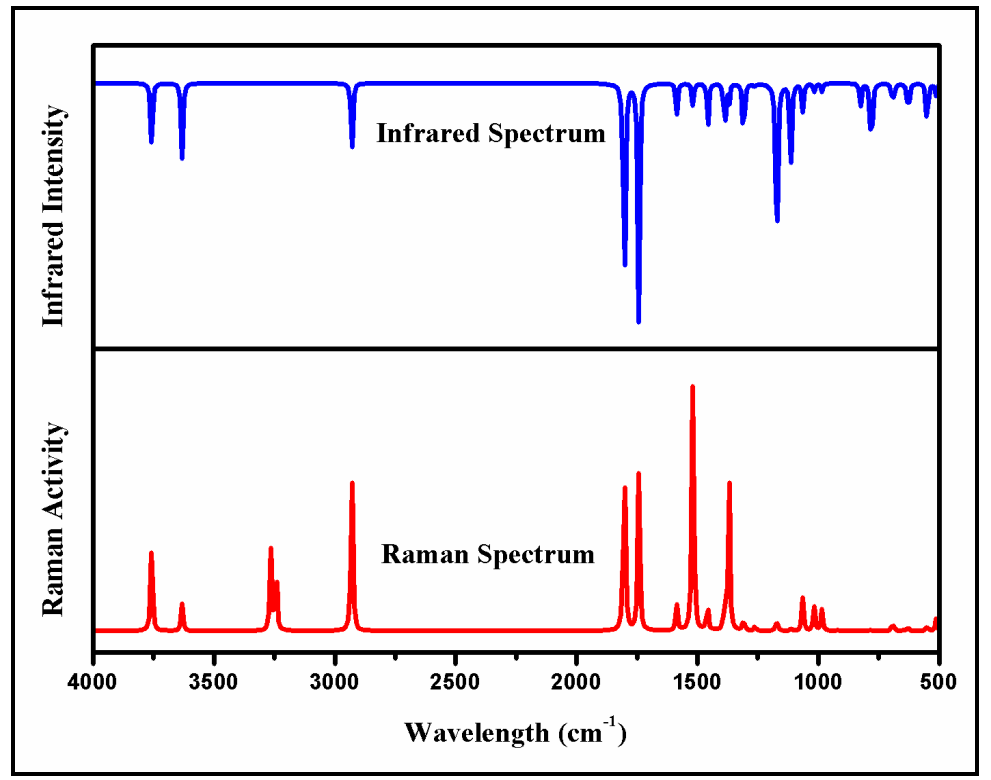

Fig.2. The infrared and Raman spectra of FHPC molecule

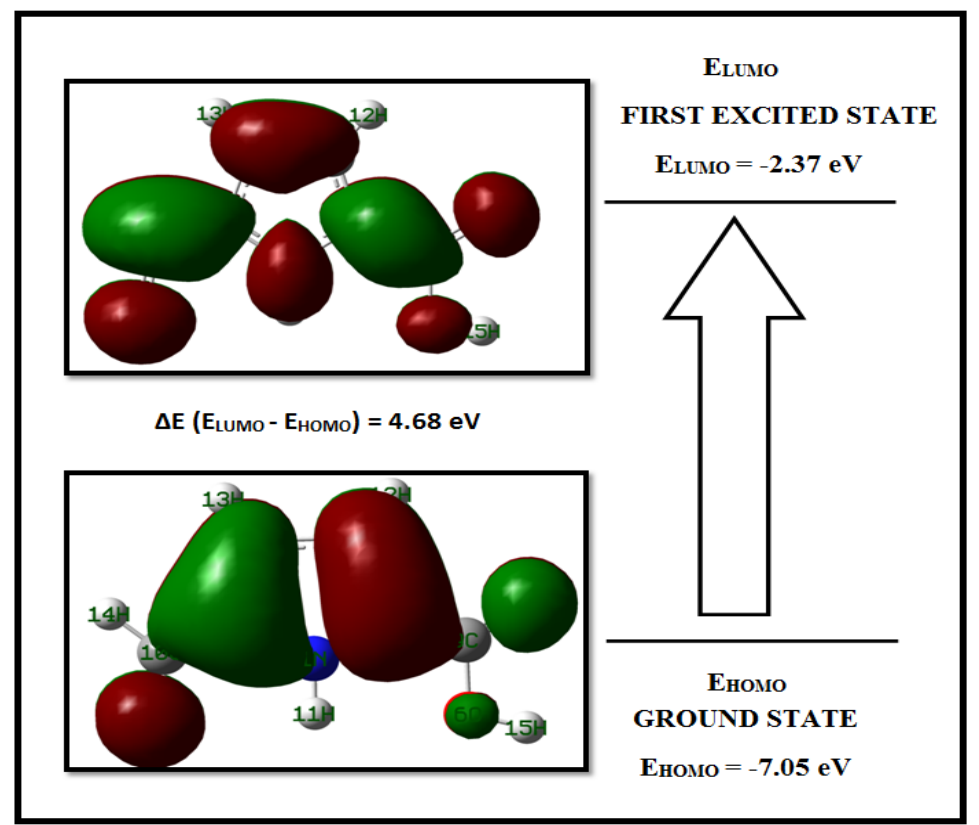

Fig.3. FMOs of the FHPC molecule

\subsection{NBO analysis}

The NBO analysis was performed using NBO 3.0 program implemented in the Gaussian 09 Program package. NBO analysis provides an effective method to understand intramolecular charge transfer (ICT) interaction and delocalization of electrons density (ED) within the FHPC molecule. For each donor (i) and acceptor $(j)$ the stabilization associated with the delocalization $i \rightarrow j$ can be estimated as

$$
\mathrm{E}_{(2)}=\Delta \mathrm{E}_{\mathrm{ij}}=\mathrm{q}_{\mathrm{i}} \frac{E_{[i, / D)}^{2}}{\varepsilon_{\mathrm{i}}-\varepsilon_{j}},
$$

where $\mathrm{q}_{\mathrm{i}}$ is the donor orbital occupancy, $\varepsilon_{\mathrm{i}}$ and $\varepsilon_{\mathrm{j}}$ are the energies of the diagonal elements and $\mathrm{F}_{(\mathrm{i}, \mathrm{j})}$ is the off-diagonal NBO Fock matrix element. The Fock matrix analysis with the stabilization energy $\mathrm{E}_{(2)}$ greater than $2 \mathrm{Kcal} \mathrm{mol}^{-1}$ was shown in Table 2 . The larger stabilization intramolecular interaction was observed between LP(N1) to $\pi^{*}(\mathrm{C} 2-\mathrm{C} 3)$ and $\pi^{*}(\mathrm{C} 4-\mathrm{C} 5)$ orbitals with stabilization energy of $39.84 \mathrm{Kcal} \mathrm{mol}^{-1}$. These interactions lead to stability and in turn to the bioactivity of the FHPC molecule $[4,5]$. 
Table 2: The NBO analysis of FHPC molecule

\begin{tabular}{|l|l|l|}
\hline \multicolumn{1}{|c|}{ Donor $(\mathbf{i})$} & \multicolumn{1}{|c|}{ Acceptor $(\mathbf{j})$} & \multicolumn{1}{c|}{$\mathbf{E}_{(2)}(\mathbf{K c a l} / \mathbf{m o l})$} \\
\hline \multirow{2}{*}{$\sigma(\mathrm{C} 3-\mathrm{C} 4)$} & $\sigma^{*}(\mathrm{C} 2-\mathrm{C} 9)$ & 5.15 \\
\cline { 2 - 3 } & $\sigma^{*}(\mathrm{C} 5-\mathrm{C} 10)$ & 5.73 \\
\hline$\sigma(\mathrm{C} 10-\mathrm{H} 14)$ & $\sigma^{*}(\mathrm{~N} 1-\mathrm{C} 5)$ & 5.52 \\
\hline$\sigma(\mathrm{N} 1-\mathrm{C} 5)$ & $\sigma^{*}(\mathrm{C} 2-\mathrm{C} 9)$ & 3.87 \\
\hline$\sigma(\mathrm{C} 2-\mathrm{C} 3)$ & $\sigma^{*}(\mathrm{~N} 1-\mathrm{H} 11)$ & 3.95 \\
\hline$\sigma(\mathrm{O} 6-\mathrm{H} 15)$ & $\sigma^{*}(\mathrm{C} 2-\mathrm{C} 9)$ & 4.45 \\
\hline$\sigma(\mathrm{N} 1-\mathrm{C} 2)$ & $\sigma^{*}(\mathrm{C} 5-\mathrm{C} 10)$ & 3.79 \\
\hline$\sigma(\mathrm{C} 4-\mathrm{H} 13)$ & $\sigma^{*}(\mathrm{~N} 1-\mathrm{C} 5)$ & 3.08 \\
\hline$\sigma(\mathrm{C} 3-\mathrm{H} 12)$ & $\sigma^{*}(\mathrm{~N} 1-\mathrm{C} 2)$ & 3.09 \\
\hline \multirow{2}{*}{$\sigma(\mathrm{C} 4-\mathrm{C} 5)$} & $\sigma^{*}(\mathrm{~N} 1-\mathrm{H} 11)$ & 3.72 \\
\cline { 2 - 3 } & $\sigma^{*}(\mathrm{C} 3-\mathrm{H} 12)$ & 4.18 \\
\hline \multirow{2}{*}{$\mathrm{LP}(\mathrm{N} 1)$} & $\pi^{*}(\mathrm{C} 2-\mathrm{C} 3)$ & 39.84 \\
\cline { 2 - 3 } & $\pi^{*}(\mathrm{C} 4-\mathrm{C} 5)$ & 39.84 \\
\hline
\end{tabular}

\section{Conclusion}

Conformational analysis was carried out and the most stable molecular structure of the FHPC molecule was predicted using DFT/B3LYP method with 6-31G basis set using Gaussian 09 program. The FHPC molecular structure was optimized using DFT/B3LYP method with cc-pVTZ basis set. The vibrational spectral analysis was performed based on PED calculation. The FMOs related molecular properties such as ionization energy, electron affinity, global hardness, chemical potential, electrophilicity index and softness values were calculated. The band gap energy of the FHPC molecule agrees well with the reported bioactive pyrrole derivatives. The FMOs and NBO studies confirm the bioactivity of the FHPC molecule.

\section{Acknowledgements}

We thank our college management for encouragement and permission to carry out this work and also thank Department of Physics, N.M.S.S.V.N college, Nagamalai, Madurai-19, for providing the Gaussian 09 program package.

\section{References}

[1] Varun Bhardwaj, Divya Gumber, Vikrant Abbot, Saurabh Dhimana and Poonam Sharma RSC Adv., 5, 2015, 15233-15266.

[2] M. S. Mohamed, S. A. Ali, D. H. A. Abdelaziz and Samar S. Fathallah , Biomed Research International, 2014.

[3] Gaussian 09, Revision A.1, M. J. Frisch et al, Gaussian, Inc., Wallingford CT, 2009.

[4] R. Mohamed Asath, R.Premkumar, T. Mathavan, A. Milton Franklin Benial, Spectrochimica Acta Part A: Molecular and Biomolecular Spectroscopy, 175, 2017, 51-60.

[5] G. Mahalakshmi, V. Balachandran, Spectrochemica Acta Part A: Molecular and Biomolecular Spectroscopy, 2015, DOI: 10.1016/j.saa.2014.06.157 